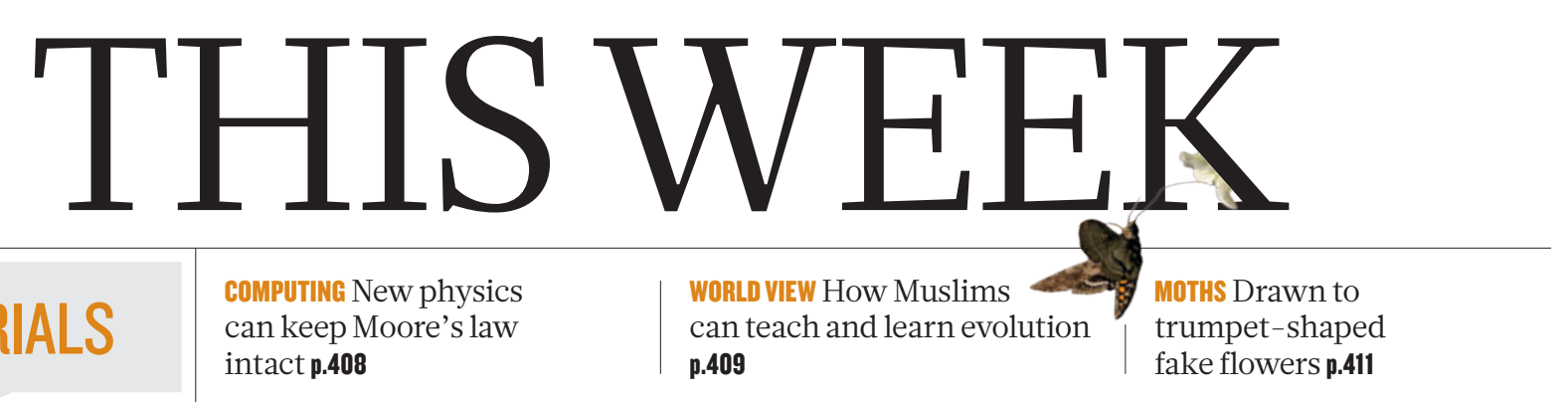
can keep Moore's law intact $\mathbf{p . 4 0 8}$
WorL VIEW How Muslims p.409 trumpet-shaped

fake flowers $\mathbf{p . 4 1 1}$

\title{
Highway to health
}

\section{Africa has an ambitious and welcome plan for a continent-wide centre for disease control - but if the agency is to live up to its promise, it will need substantially better resources.}

I $\mathrm{n}$ light of the ongoing Ebola epidemic in West Africa, it is entirely sensible that the African Union intends to set up a pan-continental organization to guard against the ravages of infectious disease. The African Centres for Disease Control and Prevention (ACDC), as the agency is called, will be modelled not on the massive US CDC, but on the smaller European Centre for Disease Prevention and Control (ECDC). Although the goal is excellent and the effort should be cautiously welcomed, the plans for the African agency are woefully inadequate. In terms of funds and staff — at least initially — it will be in no position to achieve its lofty ambitions.

There is no exact definition of a CDC other than a public-health agency, often with a focus on infectious diseases. The US CDC was created in 1946 with around 400 staff members and an annual budget of some US\$10 million (worth \$120 million today), largely to tackle malaria in the US south. It now has a staff of 15,000 and a whopping \$7-billion annual budget, covering the entire spectrum of health issues - from detecting and responding to infectious-disease outbreaks worldwide, to control and prevention of non-communicable diseases, bioterrorism, workplace injuries and environmental health threats.

The past 15 years have seen a proliferation of CDCs and equivalent organizations worldwide, in part because of awareness of the need to improve responses to infectious-disease threats, prompted in particular by the 2003 epidemic of severe acute respiratory syndrome (SARS). But their organizational models are diverse. The Public Health Agency of Canada - created in 2004 after SARS outbreaks revealed weaknesses in the country's response - is a smaller version of the US CDC, with 2,400 employees and a budget of Can\$633 million (US\$517 million).

The ECDC is different. Unlike the US and Canadian organizations, the Stockholm-based agency has no in-house laboratories. It acts instead as a coordinator, drawing on a network of research labs and national health-protection bodies to reinforce disease surveillance and response. The highly respected agency has a relatively modest budget of $€ 60$ million (US\$64 million), and 300 staff members.

The ACDC, to be based for now in Addis Ababa, would coordinate national resources and labs, as well as pan-African networks including the African Field Epidemiology Network and the African Network for Drugs and Diagnostics Innovation. It would focus on infectious diseases. But the similarities with the ECDC end there.

The ACDC's budget for July 2015 to December 2016 calls for just US\$6.9 million, and the centre would initially have just 11 staff members, including management and 5 epidemiologists. These resources are hopelessly inadequate to tackle the agency's long list of stated ambitions, which include not only helping to prevent, detect and respond to disease outbreaks, but also strengthening health systems and conducting regional and national risk assessments. The African Union has declined to say what funding it hopes the ACDC will attract beyond this start-up phase. Its backers need to commit funding now for at least five to ten years - experts say that $\$ 60$ million and 300 staff members

would be the absolute minimum needed.

That Africa seems to want to assume political ownership of its response to public-health emergencies, rather than relying largely on outside agencies and support, can only be welcomed. Yet there is a risk that the creation of this skeletal agency might provide an excuse for complacency and inaction by politicians in Africa and globally. And the

"That Africa wants to assume political ownership of its response to public-health emergencies can only be welcomed." underlying problems that leave many countries vulnerable to disease outbreaks will not be solved by an African health agency alone, however robust and however desirable.

As the Ebola epidemic has cruelly highlighted, what Africa lacks most are proper health systems and labs. There is a drastic shortage of health-care workers, with only a few dozen physicians per million people. Yet there are no serious national or international plans to reinforce public-health capacities.

An alphabet soup of organizations involved in global health and disease detection and prevention has developed over the past 20 years, yet proved incapable of reacting promptly when the Ebola threat emerged. These groups' often overlapping and duplicated efforts must be better coordinated to prevent and mitigate future health crises. But there is a danger that with concern over Ebola fading, governments will lapse back into old habits, and that the stark lessons of the epidemic will not be taken fully on board.

\section{Decoupled ideals}

\section{'Ecomodernist Manifesto' reframes sustainable development, but the goal remains the same.}

$\mathrm{H}$ umanity faces two fundamental challenges this century. The first is to lift billions of people out of poverty and give them the opportunity to live healthy and dignified lives. The second is to ensure that this development does not destabilize the climatic and ecological systems that have enabled the rise of humans and other life on Earth. The problem is that these two goals are increasingly at odds.

Reconciling the twin imperatives of conservation and development is not easy. 'Sustainable development' is a catchphrase that neatly defines what the world must ultimately achieve, but nobody knows precisely what it looks like at full scale. Later this year, governments will finalize a set of sustainable development goals to guide international aid (see also page 432 ), and in December global leaders will gather to discuss the latest climate agreement at a summit in Paris. Any deal will be burdened 
by inevitable compromises that allow space for polluting development as the world seeks better and cheaper solutions.

The latest attempt to create a framework for thinking about this dilemma comes from 18 environmental activists and academics, who published an 'Ecomodernist Manifesto' last week (see go.nature.com/ f89sls). The essay paints a hopeful picture of technological progress while placing importance on the kind of intensive development that has characterized humanity's rise so far. Only by concentrating our impact within the urban, industrial and agricultural context can we achieve a "good Anthropocene", or age of human influence, the authors argue.

Coal, oil and natural gas have improved many lives, and the essay points out that the long arc of development is already tending towards better, cleaner and more-efficient energy technologies - just not fast enough. At least in the short term, the authors contend, poor countries are right to focus on improving the lives of their citizens, even if that means expanding their use of fossil fuels until cheaper and cleaner solutions are available. These ideas are framed in terms of a larger "decoupling of humanity from nature". What this means, precisely, is left to the imagination, but the essay also underscores the role of modern agriculture, which has freed up labour, enabled the rise of cities and reduced the amount of land that we need to feed humanity. Rather than lament this trend, the authors argue that it must be encouraged and hastened.

The essay stands in sharp contrast to the gloomy outlook often provided by environmentalists and scientists. A little scepticism is warranted. For the long haul, the authors place faith in a new generation of solar cells combined with efficient energy-storage technologies, advanced nuclear fission - and even fusion energy. In the medium term, hydropower could play a part, in the same way that technologies
"Governments cannot write people out of the equation." for the capture and sequestration of carbon could improve fossil fuels over this time scale. The authors focus on large-scale power generation, but may be too quick to write off current wind and solar technologies, which can have a useful role in reducing demand for centralized power today. The wise deployment of efficient bioenergy resources may also be helpful, in tandem with agricultural intensification.

It is not yet clear what the climate fix will look like. What is clear is that governments need to invest in a portfolio of energy research, development and demonstration. They must implement strong climate policies that will push companies towards technologies that produce less air pollution and fewer greenhouse-gas emissions. They need to invest in agricultural research to secure the necessary food crops, and provide farmers and ranchers with the tools required to maximize production. And they need to set limits on the land that can be developed.

Governments cannot write people out of the equation, and hard choices will have to be made. But the first step is to point everybody in the right direction. Human ingenuity takes many forms, and we may yet surprise ourselves.

\section{More from Moore}

\section{Moore's law is approaching physical limits: truly novel physics will be needed to extend it.}

$\mathrm{H}$ ail Gordon Moore: 19 April marked the famous prediction by the (less) famous man that the late twentieth century would herald massive increases in computing power, stimulating the technological age.

Electronics and information technology now touch almost every aspect of life. Kicking off with the invention of the integrated circuit in 1958, the continuing electronics revolution is, in large part, down to the technology industry's faithful compliance with what came to be known as Moore's law.

In 1965, Moore, a chemist turned electronic engineer, noticed that in the years since the first integrated circuits were built, engineers had managed to roughly double the number of components, such as transistors, on a chip every year. He also predicted that the rate of component shrinkage - which he later revised to a doubling every two years - would continue for at least another decade.

The semiconductor industry never looked back. It has continued to shrink transistors and produce computer chips that combine increasingly high performance and functionality.

For the first few decades, the semiconductor industry met Moore's law mainly through feats of engineering genius and gigantic strides in manufacturing processes. But the key role of fundamental science is also worth remembering, especially as researchers today seek ways to maintain the rate of progress.

The invention of the transistor at Bell Laboratories in Murray Hill, New Jersey, in the 1940s was firmly based on the development of semiconductor band theory. And scientific breakthroughs played an important part in the subsequent developments of technology. Notably, in 1970, the Russian physicist Nikolay Basov and collaborators developed excimer lasers that would later be used to etch tiny circuit patterns on the silicon wafers from which chips are made.

The 1990s called for further innovation. Until then, as transistors became smaller, their speed and energy efficiency increased.

But when the components reached around 100 nanometres across, miniaturization began to have the opposite effect, worsening performance. Chip-makers such as Intel, which Moore co-founded, and IBM again looked to basic science to improve the performance of transistor materials. Major help came from condensed-matter physicists. They had known for decades that the ability of silicon to conduct electricity improves substantially when its crystal lattice is stretched - for instance, by layering it on another crystal in which the atoms have a different spacing. Engineers introduced strained silicon into chips in the 2000s, and Moore's law stayed true for several more years.

State-of-the-art microprocessors now have transistors that are just 14 nanometres wide, and Moore's law is finally approaching the ultimate physical limits. Waste heat in particular has become a source of concern. It has already caused one form of Moore's law - the exponential acceleration of computer 'clock speed' - to grind to a halt. Power-hungry chips also limit the ability of mobile devices to survive more than a few hours between charges.

The introduction of advanced materials such as hafnium oxide, which provides insulation even when it is just a few atomic layers thick, has managed to keep chips a bit cooler. Heroic efforts might yet bring one or two more generations of smaller transistors, down to a size of perhaps 5 nanometres. But further improvements in performance will require fundamentally new physics.

Where are we headed? Transistors that use quantum tunnelling, perhaps? Or those in which currents transport quantum spin rather than electric charge? Labs around the world are experimenting with approaches and materials that could drastically cut energy consumption. One avenue that could be exploited is the inherent stability of the collective 'topological' properties of atoms: a modern twist on the ancient practice of encoding information by tying knots. Some researchers are trying out radical 'neuromorphic' circuit architectures inspired by the plasticity of the brain's neuronal networks.

A principle that works well in a physics lab will not necessarily translate into something that can be mass-produced. And inevitably, most of today's attempts will lead nowhere. Society should

$\rightarrow$ NATURE.COM To comment online, click on Editorials at: go.nature.com/xhunqv have confidence, however, that somewhere, somehow, basic science will provide a way to maintain progress. Moore should be proud that we have not yet found the exception that proves his law. 